\title{
Desain Autofill Smart Dispenser dengan Sistem Kendali Volume Air Otomatis dan Pengendali Berbasis Android
}

\author{
Asriyadi $^{1}$, Dodi Tafrant ${ }^{2}$ dan Ciksadan $^{3}$ \\ 1,3. Jurusan Teknik Elektro, Politeknik Negeri Sriwijaya, Jln. Srijaya Negara, Palembang, 30139, Indonesia \\ 2. Jurusan Teknik Mesin, Politeknik Negeri Sriwijaya, Jln. Srijaya Negara, Palembang, 30139, Indonesia
}

E-mail: asriyadi@polsri.ac.id

\begin{abstract}
Abstrak
Air memiliki manfaat yang sangat besar bagi kehidupan manusia terutama untuk kebutuhan sehari-hari. Kebutuhan air minimal setiap orang perharinya adalah 121 liter baik itu untuk minum dan masak, cuci, mandi serta keperluan ibadah. Namun pemenuhan kebutuhan air ini sering mengalami kendala di kota-kota besar khususnya kantor dan pabrik. Agar persediaan air minum ini mudah dijangkau maka digunakan dispenser sebagai media untuk menampung air galon. Untuk tujuan tersebut diatas, maka pada penelitian ini dibahas tentang rancang bangun autofill smart dispenser dengan sistem otomatisasi dan berbasis android untuk memudahkan pengisian air pada gelas dan mencegah air minum tumpah dan cepat habis. Waktu pengisian dispenser berbasis android dimana rata-rata pengisian dispenser berbasis android adalah 17,96 detik dan dispenser otomatis sebesar 18,28 detik.
\end{abstract}

Keywords: Android, Arduino, Dispenser, Sensor

\section{Pendahuluan}

Air memiliki manfaat yang sangat besar bagi kehidupan manusia terutama untuk kebutuhan sehari-hari. Kebutuhan air minimal setiap orang perharinya adalah 121 liter baik itu untuk minum dan masak, cuci, mandi serta keperluan ibadah. Berdasarkan survei juga disebutkan bahwa kebutuhan air minimal bagi orang Indonesia yaitu 70 liter/hari per orang.

Manusia juga membutuhkan air untuk memenuhi lebih dari $60 \%$ cairan dalam tubuh agar tidak mengalami dehidrasi. Namun pemenuhan kebutuhan air ini sering mengalami kendala di kota-kota besar khususnya kantor dan pabrik. Hal ini disebabkan oleh lokasi persediaan air minum yang relatif jauh ataupun penempatan air minum yang tidak strategis dan praktis. Agar persediaan air minum ini mudah dijangkau maka digunakan dispenser sebagai media untuk menampung air galon.

Pemakaian dispenser dapat lebih efisien dan efektif apabila menggunakan sistem otomatisasi pada kran dan pompa air sehingga menghemat persediaan air minum yang ada. Restoran-restoran berskala besar dan restoran cepat saji juga sudah banyak menggunakan dispenser otomatis di seluruh dunia. Tujuan penggunaan dispenser otomatis ini adalah untuk mengatasi kelemahan pada dispenser manual.
Untuk tujuan tersebut diatas, maka pada penelitian ini dibahas tentang rancang bangun autofill smart dispenser dengan sistem otomatisasi dan berbasis android untuk memudahkan pengisian air pada gelas dan mencegah air minum tumpah dan cepat habis. Dispenser ini dirancang dengan menggunakan Arduino Uno sebagai mikrokontroller yang berfungsi mengendalikan perangkat, sensor photodioda sebagai pendeteksi keberadaan gelas dan sensor ultrasonik untuk mendeteksi ketinggian dan volume air. Agar lebih praktis, pengisian air dilakukan dengan menggunakan pompa air dan kran otomatis yang ditambahkan pada dispenser. Selain sistem otomatisasi, dispenser ini juga dilengkapi dengan sistem pengontrol android apabila sstem otomatisasi tidak berfungsi dengan baik.

\section{Metode Penelitian}

Penelitian ini menitikberatkan pada rancang bangun alat autofill smart dispenser otomatis berbasis android dimana dalam perancangan alat ini terdapat 2 tahapan yang dilakukan yaitu tahap perancangan hardware dan perancangan software. Perancangan hardware meliputi perancangan perangkat elektronik Perancangan mekanik dan perakitan perangkat. Untuk tahapan yang kedua adalah perancangan software yang terdiri dari pemrograman perangkat Arduino menggunakan software IDE yang berfungsi sebagai pusat kendali dan pemrosesan data dan pembuatan aplikasi android 
menggunakan software android studio sebagai media pengendali dispenser.

Berikut ini adalah diagram alir proses perancangan Autofill Dispenser dengan sistem kendali volume air berbasis android dari awal hingga akhir proses yang terdiri dari proses perancangan, perakitan dan kemudian pengujian alat yaitu :

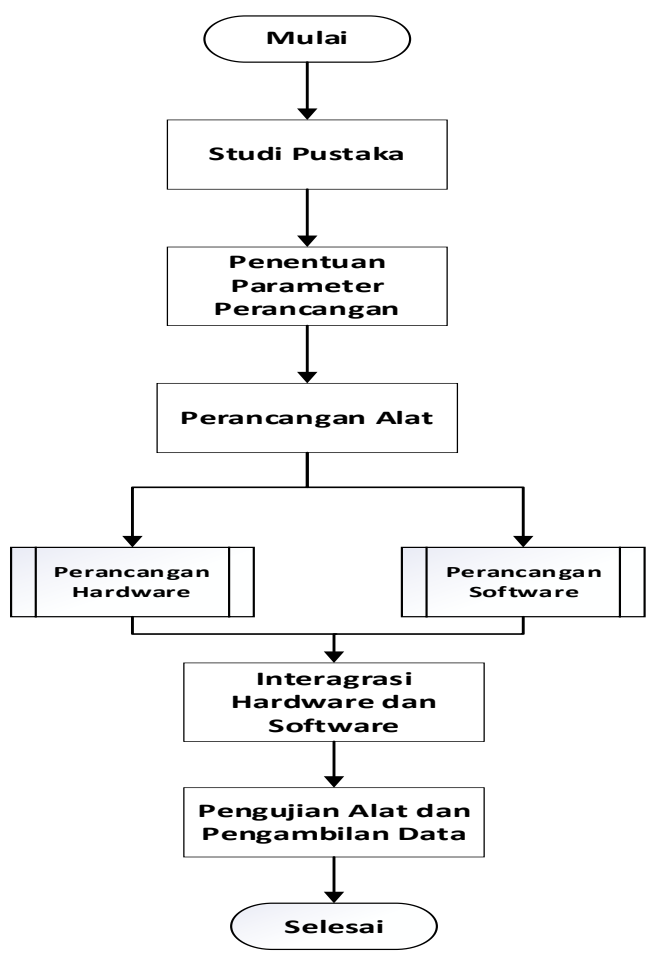

Gambar 1. Flowchart perancangan alat

Selain diagram alir perancangan alat diatas, blok diagram rangkaian juga merupakan bagian terpenting dalam perancangan alat karena ini memuat seluruh gambaran perangkat yang ingin dirancang sekaligus skema alur kerja alat. Gambar 2 memperlihatkan blok diagram Autofill Smart Dispenser dengan sistem kendali volume air berbasis Android.

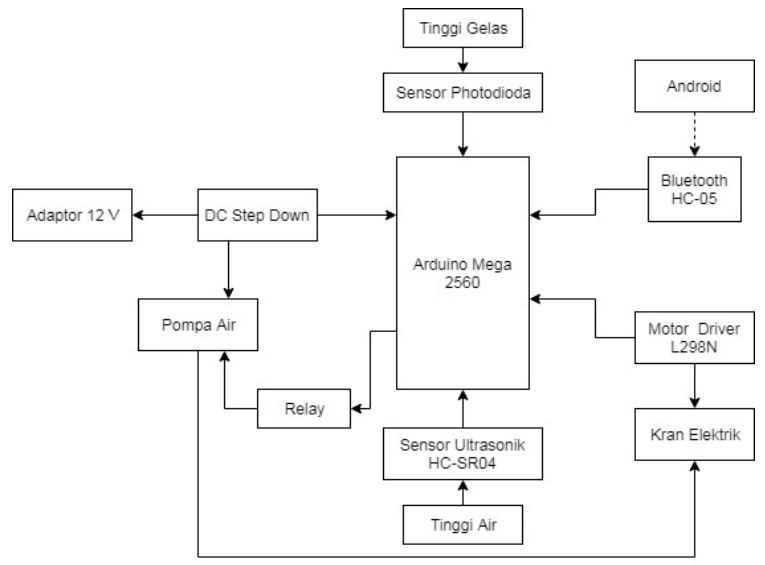

Gambar 2. Blok Diagram Autofill Smart Dispenser a. Perancangan Hardware

Dalam Perancangan Hardware, terdapat 3 tahapan yang harus dilakukan dalam merancang bangun alat Autofill smart dispenser ini yaitu pertama, perancangan perangkat elektronik. Kedua, perancangan mekanik dan ketiga, perakitan perangkat. Perancangan elektronik bertujuan untuk merancang dan menyusun rangkaian elektronik yang terdiri dari arduino, sensor, motor, relay, DC step down, adaptor modul Bluetooth dan kran elektrik. Untuk memastikan perancangan elektronik bekerja dengan baik, maka seluruh komponen diukur dan diuji coba terlebih dahulu. Setelah itu baru dilakukan perancangan elektronik seperti gambar blok diagram diatas. Perancangan mekanik meliputi proses modifikasi dan penambahan alat pada dispenser. Gambar 3 dibawah ini proses modifikasi dan penambahan alat pada dispenser sebagai berikut :
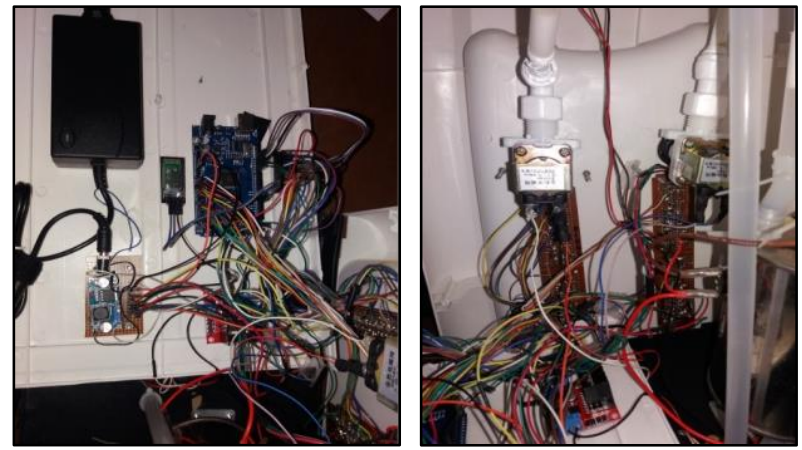

Gambar 3. Proses modifikasi dan penambahan alat pada dispenser

Tahapan yang terakhir adalah perakitan perangkat yang bertujuan untuk menyusun dan merakit seluruh komponen menjadi satu kesatuan alat. Perakitan perangkat ini dilakukan secara manual menggunakan solder dan bor dan kemudian hasil perakitan harus diperiksa menggunakan multimeter agar seluruh perangkat benar-benar terhubung. Dibawah ini adalah gambaran sketsa rangkaian yang dibuat menggunakan software untuk memudahkan dalam perakitan perangkat sebagai berikut :

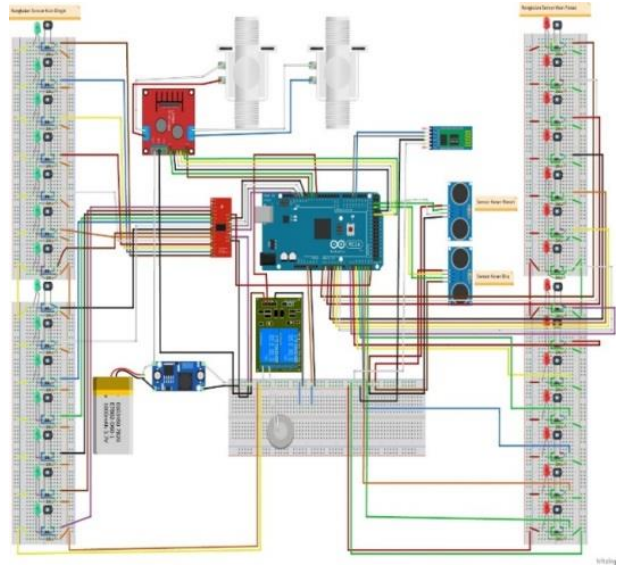

Gambar 4. Sketsa rangkaian untuk perakitan 


\section{b. Perancangan Software}

Perancangan perangkat lunak didesain dengan menggunakan software IDE Arduino. Pemrograman ini bertujuan untuk menghidupkan dan mengaktifkan seluruh perangkat elektronik yang terhubung ke Arduino. Arduino yang terprogram oleh software Arduino IDE bertindak sebagai mikrokontoller untuk menjalankan fungsi dari masing-masing perangkat tersebut. Adapun perangkat-perangkat perlu diprogram agar dapat dikendalikan oleh Arduino adalah sebagai berikut sensor, relay, Bluetooth dan motor driver.

Dibawah ini adalah Langkah-langkah perancangan perangkat lunak dalam pembuatan alat autofill smart dispenser sebagai berikut:

1. Memprogram Sensor Photodiode untuk mendeteksi keberadaan gelas pada wadah dispenser.

2. Memprogram Sensor Ultrasonik untuk menentukan ketinggian dan volume air pada gelas.

3. Memprogram motor driver untuk membuka dan menutup katub kran elektrik

4. Memprogram relay yang berfungsi untuk menghidupkan dan mematikan pompa air.

5. Memprogram bluetooth untuk terhubung dengan android.

6. Membuat aplikasi android yang bertujuan untuk pengendali kran elektrik dan pompa air pada dispenser.

\section{c. Perakitan Perangkat}

Perakitan merupakan langkah (tahap) akhir dari seluruh proses pembuatan alat ini. Proses perakitan ini berguna untuk mennggabungkan seluruh perangkat menjadi suatu kesatuan. Pada perancangan elektronik, seluruh komponen alat yang disusun kemudian diintegrasikan ke Arduino yang berfungsi sebagai mikrokontroller untuk mengatur dan mengendalikan seluruh perangkat yang terhubung. Setelah seluruh komponen alat elektronik terhubung, perangkat mekanik dirancang bangun dan digabungkan dengan perangkat elektronik. Gambar 5 dibawah ini merupakan gambar perangkat mekanik yang telah digabungkan dengan perangkat elektronik antara lain:
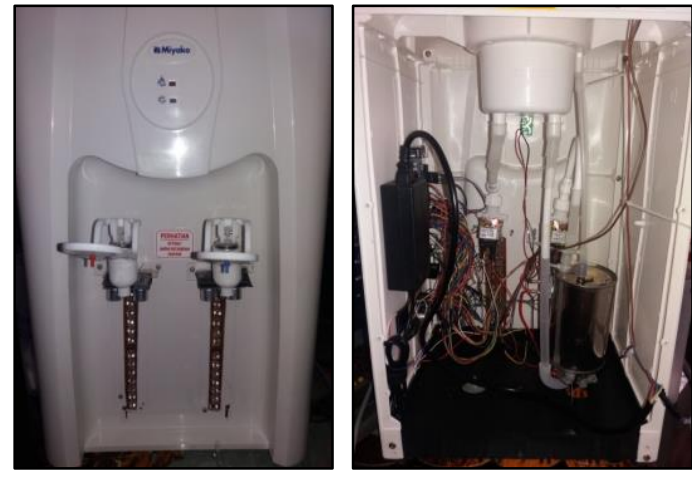

Gambar 5. Perakitan Perangkat

\section{d. Prinsip Kerja Alat}

Prinsip kerja alat ini berawal dari sensor photodiode dimana sensor ini akan mendeteksi keberadaan gelas pada dispenser dimana dispenser ini dipasang kran elektrik untuk membuka dan menutup katub kran secara otomatis. Ketika sensor photodiode mendeteksi gelas, maka katub kran elektrik akan terbuka secara otomatis dan kemudian pompa air akan mengisi air pada gelas. Apabila air pada gelas hampir terisi penuh, maka sensor ultrasonik bekerja untuk menutup katub kran elektrik dan pompa air berhenti untuk mengisi air. Jarak pendeteksian antara sensor ultrasonik dan permukaan air diatur sebesar $10,5 \mathrm{~cm}$. Kemudian untuk prinsip kerja alat menggunakan android yaitu pertama-tama, android dikoneksikan dengan modul Bluetooth pada perangkat. Setelah terkoneksi, gelas diletakkan pada dispenser dimana terdapat 2 pilihan yaitu air panas atau dingin. Selanjutnya tekan tombol ON pada aplikasi di android untuk mengisi air. Apabila air pada gelas sudah penuh, tekan tombol OFF untuk menghentikan air. Diagram alir prinsip kerja alat ditunjukkan pada gambar 3 dibawah sebagai berikut :
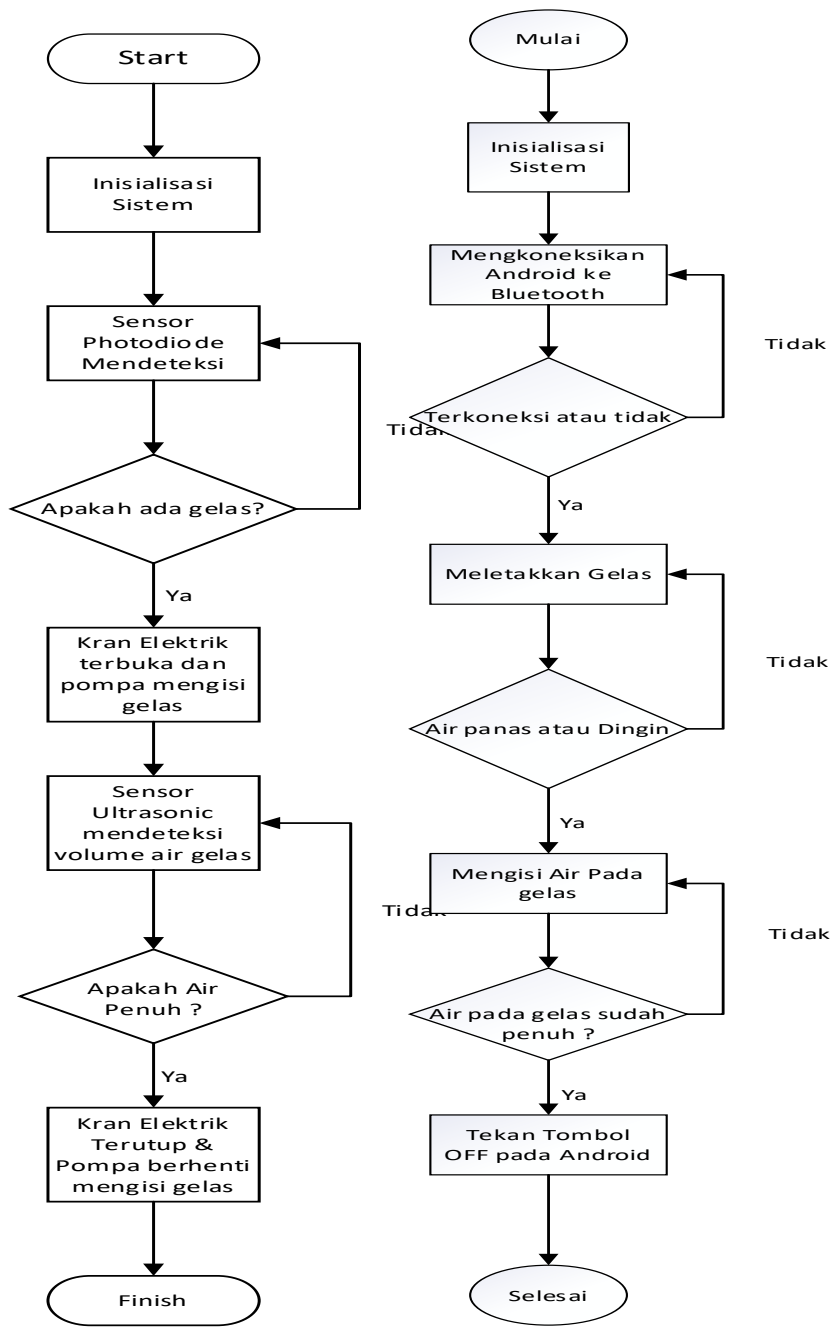

Gambar 6. Flowchart Prinsip Kerja Alat 


\section{Hasil dan Pembahasan}

Sebelum dilakukan pengukuran, seluruh perangkat dilakukan pengujian terlebih dahulu untuk memastikan bahwa perangkat dapat berjalan dengan baik. Untuk mempermudah pengukuran dan pengambilan data, ada beberapa titik pengukuran yang perlu ditentukan yaitu sebagai berikut :

a. Titik pengukuran pada tegangan input sensor photodioda beserta bilangan biner ketika ada dan tidak ada gelas.

b. Titik pengukuran tegangan input pada sensor ultrasonik

c. Titik pengukuran modul Bluetooth $\mathrm{HC}-05$

Pada titik-titik pengukuran diatas didapatkan hasil pengukuran dari masing-masing komponen alat yang diinginkan sehingga hasil pengukuran yang diamati benar-benar tepat dan akurat.

a. Titik Pengukuran Sensor Photodioda

Titik uji pengukuran sensor photodioda berada pada dua titik uji yaitu TP2(+) dan TP2(-) dimana tegangan input awal adalah $4,86 \mathrm{~V}$ dengan tegangan inputan dari DC step down sebesar 5 V. Dibawah ini adalah tabel hasil pengukuran pada sensor photodiode sebagai berikut :

Tabel 1. Hasil Titik Uji Pengukuran TP2

\begin{tabular}{ccc}
\hline Pengukuran & Ada Gelas & $\begin{array}{c}\text { Tidak Ada } \\
\text { Gelas }\end{array}$ \\
\hline 1 & $4,86 \mathrm{~V}$ & $5 \mathrm{~V}$ \\
2 & $4,69 \mathrm{~V}$ & $5,2 \mathrm{~V}$ \\
3 & $4,78 \mathrm{~V}$ & $5,1 \mathrm{~V}$ \\
4 & $4,84 \mathrm{~V}$ & $5,3 \mathrm{~V}$ \\
5 & $4,82 \mathrm{~V}$ & $5,0 \mathrm{~V}$ \\
\hline
\end{tabular}

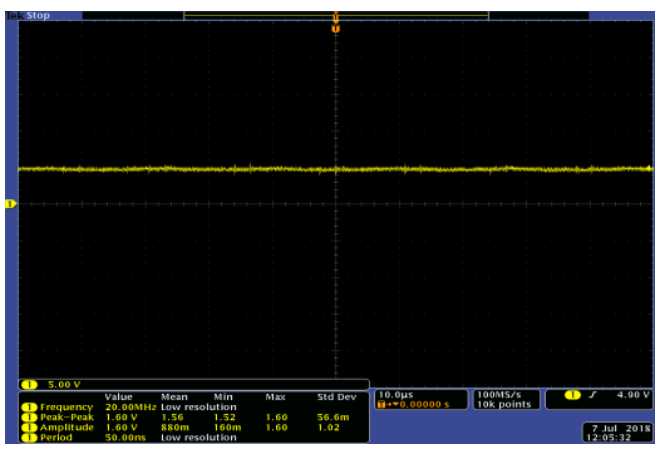

Gambar 7. Tampilan osiloskop saat tidak ada gelas

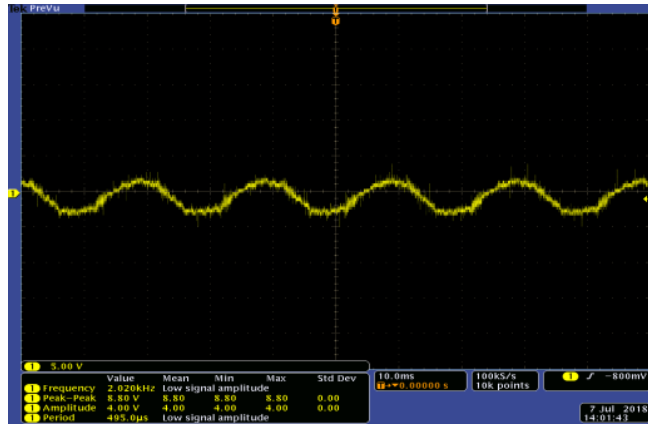

Gambar 8. Tampilan osiloskop saat ada gelas

Tabel 2. Hasil Bilangan Biner pada Serial Monitor Arduino

\begin{tabular}{ccc}
\hline $\begin{array}{c}\text { Posisi } \\
\text { Sensor }\end{array}$ & Tidak Ada Gelas & Ada Gelas \\
\hline A0 & 429 & 673 \\
A1 & 205 & 899 \\
A2 & 98 & 948 \\
A3 & 100 & 959 \\
A4 & 111 & 945 \\
A5 & 118 & 958 \\
A6 & 122 & 960 \\
A7 & 104 & 955 \\
A8 & 111 & 955 \\
A9 & 92 & 952 \\
A10 & 82 & 948 \\
A11 & 90 & 935 \\
A12 & 120 & 952 \\
A13 & 76 & 958
\end{tabular}

b. Titik Pengukuran Sensor Ultrasonik

Dari lima kali pengukuran yang dilakukan pada titik uji pengukuran pada sensor ultrasonik yaitu TP (+) dan TP3(-), didapatkan beberapa tegangan awal input ketika gelas tidak ada di dispenser dan kemudian setelah gelas diletakkan beberapa kali pada dispenser terjadi penurunan tegangan pada sensor. Data hasil pengukuran sensor ultrasonik disajikan pada tabel 3 dibawah ini: 
Tabel 3. Hasil Titik Uji Pengukuran TP3

\begin{tabular}{ccc}
\hline Pengukuran & Kran Terbuka & Kran Tertutup \\
\hline 1 & $5,10 \mathrm{~V}$ & $3.27 \mathrm{~V}$ \\
2 & $5,08 \mathrm{~V}$ & $3.28 \mathrm{~V}$ \\
3 & $5,11 \mathrm{~V}$ & $3.31 \mathrm{~V}$ \\
4 & $5,13 \mathrm{~V}$ & $3.3 \mathrm{~V}$ \\
5 & $5,15 \mathrm{~V}$ & $3.26 \mathrm{~V}$ \\
\hline
\end{tabular}

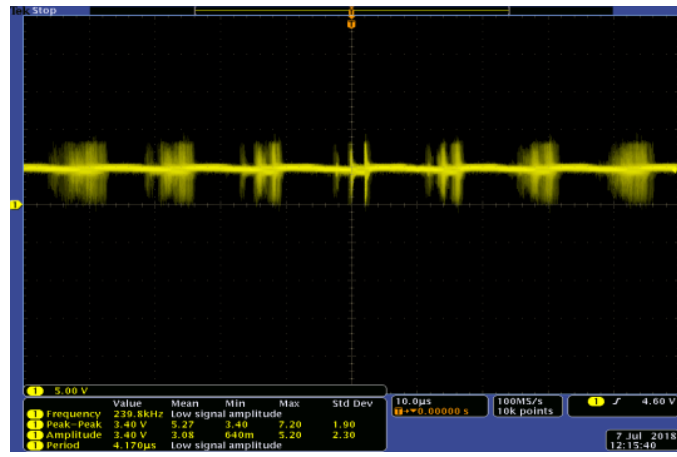

Gambar 9. Tampilan osiloskop ketika kran dispenser terbuka

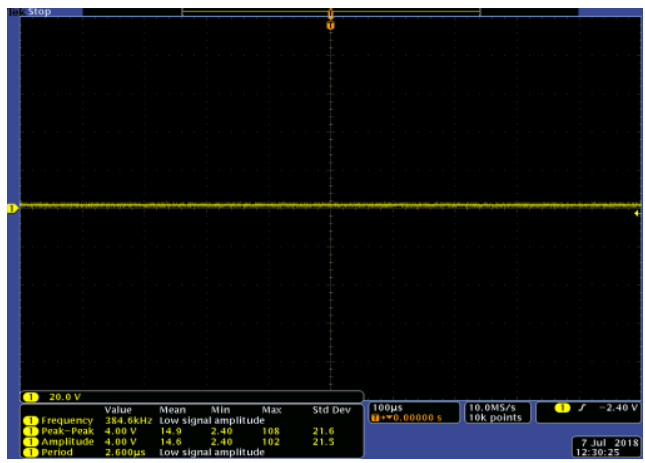

Gambar 10. Tampilan osiloskop ketika kran dispenser tertutup

c. Perbandingan waktu pengisian dispenser otomatis dan berbasis android

Pengujian selanjutnya adalah perbandingan waktu pengisian antara dispenser yang bekerja secara otomatis dengan pengisian berbasis android. Pengujian ini dilakukan beberapa kali untuk melihat kinerja dari dispenser berdasarkan dua kondisi tersebut. Dari 5 kali pengujian yang dilakukan didapatkan hasil perhitungan waktu yaitu dispenser berbasis android lebih cepat waktu pengisian dibandingkan secara otomatis. Perbandinagn hasil perhitungan waktu pengisian air oleh dispenser ditampilkan pada tabel 4 sebagai berikut:
Tabel 4. Waktu Pengisian Air pada Dispenser Otomatis dan berbasis android

\begin{tabular}{ccc}
\hline Percobaan & $\begin{array}{c}\text { Dispenser } \\
\text { Otomatis }\end{array}$ & Dispenser Biasa \\
\hline 1 & 18,3 detik & 17,7 detik \\
2 & 18,0 detik & 18,3 detik \\
3 & 18,5 detik & 17,9 detik \\
4 & 18,6 detik & 18,1 detik \\
5 & 18,0 detik & 17,8 detik \\
\hline
\end{tabular}

Kecepatan Pengisian Air pada Dispenser Otomatis dan Dispenser Biasa

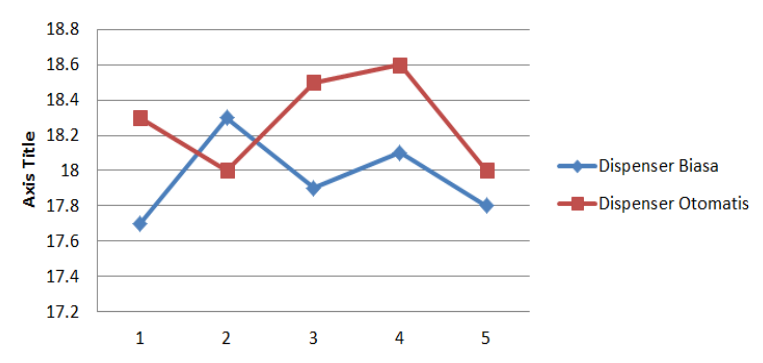

Gambar 11. Grafik Waktu Pengisian Air pada Dispenser Otomatis dan berbasis Android

d. Waktu Koneksi antara Modul Bluetooth dan Android Untuk melihat kinerja jaringan antara modul Bluetooth dengan Android, maka dilakukan uji coba koneksi jaringan pada kedua perangkat tersebut. Dalam pengujian jaringan ini, parameter uji yang diukur adalah waktu tunda koneksi jaringan antara modul dan Android. Pengujian dilakukan dengan menggunakan jarak ukur antara Android dengan modul Bluetooth pada perangkat untuk membuka dan menutup kran elektrik. Dari hasil pengujian dapat diamati bahwa semakin jauh jarak ukur antara android dan modul, maka waktu tunda yang dihasikan semakin besar. Untuk dispenser yang bekerja secara otomatis tidak berpengaruh pada waktu tunda. Sedangkan dispenser yang menggunakan pengendali android sangat berpengaruh pada lama pengisian air disebabkan bertambahnya waktu tunda dari awal pengendali dispenser hingga pengisian air. Hasil pengukuran waktu delay dengan menggunakan koneksi Bluetooth android ke Bluetooth dispenser disajikan dalam tabel 5 sebagai berikut: 
Tabel 5. Delay Koneksi Bluetooth Dispenser dan Bluetooth Android

\begin{tabular}{cccc}
\hline Percobaan & $\begin{array}{c}\text { Jarak } \\
\text { Ukur }\end{array}$ & $\begin{array}{c}\text { Tombol } \\
\text { ON-Kran } \\
\text { Terbuka }\end{array}$ & $\begin{array}{c}\text { Tombol } \\
\text { OFF-Kran } \\
\text { Tertutup }\end{array}$ \\
\hline 1 & $>1 \mathrm{~m}$ & 0,4 detik & 0,2 detik \\
2 & $>3 \mathrm{~m}$ & 0,5 detik & 0,3 detik \\
3 & $>5 \mathrm{~m}$ & 0,6 detik & 0,4 detik \\
4 & $>7 \mathrm{~m}$ & 0,7 detik & 0,8 detik \\
5 & $>9 \mathrm{~m}$ & 0,9 detik & 0,7 detik \\
6 & $>10 \mathrm{~m}$ & 0,7 detik & 0,8 detik \\
7 & $<14 \mathrm{~m}$ & 0,9 detik & 0,9 detik \\
\hline
\end{tabular}

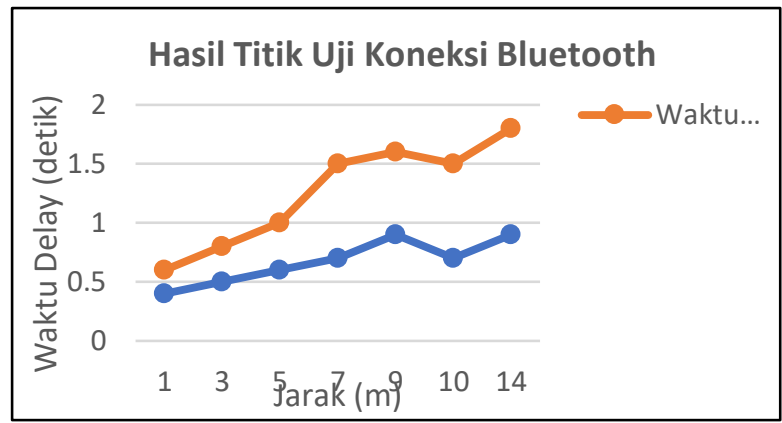

Gambar 12. Grafik Hasil Pengukuran Delay Koneksi Bluetooth

\section{Kesimpulan}

Dari hasil pembahasan diatas didapatkan beberapa kesimpulan yaitu pertama, pada titik pengujian pada sensor photodiode terjadi penurunan tegangan. Dari 5 kali pengukuran dimana tegangan awal input yaitu sebesar $5 \mathrm{~V}$, tegangan pada sensor photodiode mengalami penurunan setelah digunakan yaitu sebesar 0,2 V- 0,4 V. Kedua, Pengujian pada sensor ultrasonik juga mengalami penurunan tegangan setelah sensor bekerja. Rata-rata tegangan yang turun yaitu sebesar $1,74 \mathrm{~V}-1,9 \mathrm{~V}$ dari 5 kali pengujian. Ketiga, perbandingan waktu pengisian pada dispenser otomatis dan berbasis android didapatkan bahwa waktu pengisian pada dispenser berbasis android lebih cepat dibandingkan dispenser otomatis. Waktu pengisian dispenser berbasis android dimana rata-rata pengisian dispenser berbasis android adalah 17,96 detik dan dispenser otomatis sebesar 18,28 detik. Kesimpulan terakhir yaitu waktu tunda koneksi antara modul Bluetooth dan android mengalami kenaikan berdasarkan jarak keduanya. Semakin jauh jarak kedua perangkat tersebut maka akan semakin bertambah waktu tunda yang dihasilkan.

\section{Daftar Acuan}

[1]D. Timbowo. "Manfaat Penggunaan Smartphone Sebagai Media Komunikasi”. E-Journal: Acta Diurna," V(2). (2016).

[2] Murtiwiyati, G. Lauren. "Rancang Bangun Aplikasi Pembelajaran Budaya Indonesia Untuk Anak Sekolah Dasar berbasis Android". Jurnal Ilmiah KOMPUTASI, 12, 2,3. (2013).

[3] N. Safaat. "Pemograman Aplikasi Mobile Smartphone dan Tablet PC Berbasis Android". Bandung: Penerbit Informatika. (2012).

[4] S. Sunaryo, dkk. "Pembuatan Aplikasi Wisata Sejarah Pertempuran Surabaya 1945 Berbasis Android”. Jurnal Infra, vol. 1, p. 1, (2013).

[5] A. Sunyoto. "Teknologi (Arsitektur dan Protokol) Bluetooth". (2005).

[6] I. Oktariawan, dkk. "Pembuatan Sistem Otomasi Dispenser Menggunakan Mikrokontroler Arduino Mega 2560". E-Journal “FEMA", V(2).(2013).

[7] M. Aktanto. "Multi Ultrasonic Electronic Travel Aids (MUETA) sebagai Alat Bantu Penunjuk Jalan Bagi Tuna Netra". E-Journal "BIOSAINS”.V(18), No.(2). (2016).

[8] Anon. "Jenis-Jenis Resistor". Himpunan Mahasiswa Teknik Elektronika PENS. (2017).

[9] M. Sagita. Tugas Akhir. "Aplikasi Led Rgb Pada Lengan Robot Penyortir Kotak Berdasarkan Warna Berbasis Arduino Uno". Politeknik Negeri Sriwijaya. (2015).

[10] TP. Handayani. Tugas Akhir. "Rancang Bangun Sistem Keamanan Pintu Rumah Menggunakan Switch Magnetik Dengan Monitoring Web Bootstrap Berbasis Raspberry Pi”. Politeknik Negeri Sriwijaya. (2015). 